sun appears redder as it sinks towards the horizon, and loses more of its blue rays in the thicker atmosphere.

Gas and oil lights are richer in these penetrative rays than the arc light, which is peculiarly rich in the blue rays easily absorbed. Hence a gas jet can be seen a long distance in a fog, though, like the sun, it appears redder in tinge than usual. An arc light, on the other hand, is not seen far, however penetrative it may be in clear weather. I have often observed on London Bridge, in a fog, that the arc lamps become of a blank white; the brilliant arc seems to disappear, and the carbon points, slightly reddened, glow through the mist. The arc with its blue rays is the part which suffers most, and hence the larger the incandescent points in comparison, the likelier the light to penetrate. The ordinary electric incandescent lamp has, according to the late $\mathrm{R}$. Sabine, 20 per cent. more orange rays than daylight, a fact which may account for its greater penetrative power than the arc; but, owing to its cost, it is debarred from lighthouse work.

On the whole it would appear advisable to employ the spectroscope in the South Foreland experiments, in order to find out what the absorptive action of mists is on arc, gas, and oil lights. If it should turn out, as above indicated, that the arc fails in penetration from lack of certain yellow, orange, and red rays, it might be useful to try the effect of supplying the needful rays by mixing certain salts with the carbons.

J. MUNRO

West Croydon

\section{The Cholera Germ}

THE importance of our gaining clear ideas of the cause of cholera as soon as possible prompts me to venture to suggest the direction in which may be sought an explanation of the three propositions in NATURE (p. 26), and which "E. K." there says "appear to me to be in hopeless contradiction." The propositions are, substantially, as follows:-(I) The comma-shaped bacillus is the cause of cholera; (2) the alimentary canal is the exclusive organ of its entrance into the body; (3) the commashaped bacillus is killed by acid.

The life of most plants is destroyed by passing through the alimentary canal of animals or man, yet seeds of grasses, grains of cereals, \&c., not infrequently pass through animals without destruction, and afterwards germinate and reproduce their kind. Seeds of small fruits sometimes pass uninjured through the human body and through birds. Spores of bacilli are known to withstand treatment which is destructive of the bacilli themselves. Unless the commia shaped bacillus is exceptional in not forming such spores, it seems to me that the three foregoing propositions may not only be thus explained, but that they may soon supply an explanation of what has been long waiting explanation, namely, the fact that the dejections of cholera patients are not often, if ever, found infectious when first voided, but soon become infectious. This accords perfectly with the three propositions if we suppose that the comma-shaped bacillus, soon after being voided in the dejections, forms spores which are capable of resisting the acids of the stomach. It seems very important to have this point investigated. To plead for such investigation, by whoever has opportunity, is a main object of this letter.

The many instances of the outbreak of cholera in this country (U.S.A.) immediately after infected baggage has been unpacked, might then receive easy explanation; the spores, being inhaled with the breath, would be likely to lodge in the posterior nares and pharynx, be swallowed, passed through the stomach, and in the nutritive alkaline fluids of the intestines find a congenial soil in which to germinate, forming comma-shaped bacilli giving off their poisonous by-product which seems to have such baneful influence on the human nervous system.

$$
\text { Lansing, Michigan, August } 8 \text { HENRy B. BAKER }
$$

\section{School Museums}

Dr. GLADSTONF, do 3 not allude to botanical specimens in his communication to NATURE last week (p. 384), but these can form a very interesting addition. In my father's parish school of Hitcham, he had a long row of phials fixed against the wall of the class-room, with the name of every plant of the parish attached below. These were kept constantly supplied by the children all through the summer. Whoever first brought any species had a small reward. The School Herbarium was entirely made by the children; and for the last twenty-five years I have used for teaching purposes specimens dried, mounted, and labelled by the children of Hitcham School. Should any one desire further details on the subject of botany in schools, I shall be very glad to communicate with such.

Drayton House, Ealing

George Henslow

THE circulating loan collections of natural history specimens, referred to by Dr. Gladstone in his letter on this subject as being established at Liverpool, have been provided and organised not by the School Board but by the Free Library and Museum Committee of the Corporation. They owe their origin almost entirely to the Rev. H. H. Higgins, chairman of the Museum Sub-Committee, and their great value is due to the close personal attention which that gentleman and the Curator of the Museum (Mr. T. J. Moore) have bestowed on them. The specimens included in the collections are not only typical, but are of excellent quality, and cannot fail to arouse the interest of the children before whom they are brought. So far as the experiment has already gone it has proved very successful, and deserves to be widely known.

Having had the pleasure of bringing the matter of these collections forward in the discussion on Dr. Jex-Blake's paper at the Educational Conference, I should be glad if you would allow me to make this correction as to their origin.

21, Verulam Street, Liverpool, Aug. 25

W. HewitT

\section{The Permanency of Continents}

As a small contribution to this theory, the Cornish beaches may furnish a quota. They are entirely composed of finely comminuted shells, with a small admixture of fragments of Bryozoa, spines of minute Echinoderms, and occasional mica flakes. Such sandy beaches occur in small bays, and if subjected to metamorphic action would form lenticular masses of limestone intercalated between the strata deposited above and below them. Hence such occurrences of limestone might well indicate such a littoral origin as is here displayed.

St. Ives

George Henslow

\section{Carnivorous Wasps}

I ONCE witnessed a somewhat similar feat to that meritioned by "F. N." (p. 385). It was at a wayside inn in the Eifel. The tablecloth was covered with flies. The window was closed excepting one small'corner at the top. A wasp entered, came direct to the table, but instead of attacking some stewed sfruit thereupon, instantly seized a fly, bore it off, and after whirling round with it, made straight for the small means of exit and vanished.

One evening when at College a small beetle was flying round and round, but at some height over the lamp. A spider on the ceiling watching his opportunity, suddenly dropped upon it and caught it fying! He then ran up with it and began winding a belt of silk round its body. However the beetle ultimately managed to slip its meshes and escaped.

\section{George Henslow}

IN reply to your correspondent "F. N.," I would say that, while I do not recollect to have seen wasps, under natural conditions and in the open air, attacking flies, I have frequently seen a wasp, when shut up in a room, or supposing himself to be so (for wasps are very stupid in finding their way out of a room), attack and partially devour the common house-fly. I yesterday witnessed an instance of cannibalism on the part of the wasp. One of my drawing-room windows was closed, and on this seven or eight wasps were engaged in a fruitless struggle against the irritating and inexplicable glass, instead of escaping, as they might have done, through the other windows, which were open, One of them, more languid and weary than the rest, was crawling slowly up and down near the corner of the pane. Some minutes afterwards, looking up from my book, I noticed two of the other wasps engaged in furiously attacking this individual. After a few seconds, one of the opponents, perhaps endowed with higher moral susceptibilities than the other, flew away. The other seized upon the thorax of the now moribund wasp, and, after a few moments, began devouring him. I watched the process for a minute or two, and then the cover of a book put an end to the existence of the cannibal and of his prey.

A day without food reduces a wasp to a state of famine, and it might be easily ascertained whether he does not commonly, 